\title{
Proposta de Zoneamento Ambiental para o Parque Estadual Mata do Pau Ferro, Paraíba, Brasil
}

\author{
Environmental Zoning proposal to the Pau Ferro Forest State \\ Park, Paraíba, Brazil
}

\author{
Jean Oliveira Campos, Universidade Estadual da Paraíba, Brasil, jeannolliveira@gmail.com \\ (1) https://orcid.org/0000-0002-2874-754X \\ Valéria Raquel Porto de Lima, Departamento de Geografia, Universidade Estadual da Paraíba, Brasil, \\ vrportol@yahoo.com.br \\ https://orcid.org/0000-0001-7744-3502
}

Resumo: O bioma Mata Atlântica é uma das áreas de maior biodiversidade do mundo e uma das mais degradadas pela ação antrópica, em vista disso, constitui uma área prioritária para a implantação de Unidades de Conservação da Natureza. A escassez de recursos financeiros e baixa disponibilidade de pessoal representam as principais dificuldades enfrentadas pelos órgãos ambientais para a manutenção das áreas protegidas. No estado da Paraíba, o Parque Estadual Mata do Pau Ferro abriga um dos fragmentos de Mata Atlântica mais representativos do estado. Situado no Planalto da Borborema, o fragmento está circundado pelo bioma Caatinga, apresentando-se assim, como um Refúgio Florestal. O Parque ainda não possui Plano de Manejo implementado, pelo que não dispõe de zoneamento, o que tem dificultado a sua gestão. Diante do exposto, o presente trabalho se propõe a elaborar uma proposta de Zoneamento Ambiental para o Parque Estadual Mata do Pau Ferro. Para a elaboração da proposta de Zoneamento Ambiental foram realizadas as seguintes etapas: levantamento bibliográfico, aquisição de imagens do satélite Sentinel-2B, levantamento das bases cartográficas da área de estudo e trabalhos de campo para mapeamentos, coleta de dados e registros fotográficos. Os dados foram processados através do software livre QGIS 2.18.25, e posteriormente utilizados para elaboração dos mapas ambientais. A partir da análise dos mapas e com base nos critérios do Instituto Brasileiro do Meio Ambiente e dos Recursos Naturais Renováveis - IBAMA foi realizada a delimitação das zonas. Os resultados evidenciaram o potencial do Parque para preservação da biodiversidade, manutenção do sistema hídrico da barragem Vaca Brava, turismo e educação ambiental. Foi identificada também a presença de conflitos e áreas degradadas no interior da unidade. A cobertura da Zona de Amortecimento apresentou dominância de pastagens e presença de fragmentos florestais com potencial para o estabelecimento de corredores ecológicos. Com o Zoneamento Ambiental foram estabelecidas sete zonas: Zona Intangível; Zona Primitiva; Zona de Uso Extensivo; Zona de Recuperação; Zona de Uso Conflitante; Zona de Ocupação Temporária; e Zona de Uso Especial. O zoneamento apontou a necessidade de mudança de uso das áreas, resolução de conflitos internos e maior fiscalização por parte dos órgãos gestores. As elaborações cartográficas e dados levantados podem ser utilizadas como subsídios ao planejamento e manejo da Unidade de Conservação, visando o alcance dos objetivos traçados para a categoria.

Palavras-chave: Mata Atlântica; Unidade de Conservação; Zoneamento Ambiental.

\begin{abstract}
The Atlantic Forest biome is one of the most biodiverse areas in the world and one of the most degraded by anthropic action, therefore constitutes a priority area for the implementation of Conservation Units. The scarcity of financial resources and the low availability of personnel represents the main difficulties faced by environmental agencies in maintaining protected areas. In the state of Paraíba, the Pau Ferro Forest State Park is a shelter of one of the Atlantic Forest fragments most representative of the state. Situated in the Borborema Plateau, the fragment is surrounded by Caatinga biome, thus presenting itself as a Forest Refuge. The Park does not have a Management Plan implemented yet, therefore it has no zoning, which has been difficulting its management. Given the above stated, the present work proposes to elaborate an Environmental Zoning proposal for the Pau Ferro Forest State Park. To elaborate the Environmental Zoning proposal the following steps were
\end{abstract}


performed: bibliographic survey, acquisition of Sentinel-2B satellite images, cartographic basis survey of the study area and fieldwork for mapping, data collection, and photographic records. The data was processed using the free software QGIS 2.18.25 and later used for the elaboration of the environmental maps. From analyzing the maps and based on the criteria of the Brazilian Institute of Environment and Renewable Natural Resources - IBAMA, was performed the delimitation of the zones. The results showed the potential of the Park to preserve biodiversity, maintain the Vaca Brava dam's water system, tourism, and environmental education. It was also identified the presence of conflicts and degraded areas inside the unit. The coverage of the Dampen Zone showed the dominance of pastures and the presence of forest fragments with potential for the establishment of ecological corridors. With the Environmental Zoning, were established seven zones: Intangible Zone; Primitive Zone; Extensive Use Zone; Recuperation Zone; Conflicting Use Zone; Temporary Occupation Zone; and Special Use Zone. The zoning pointed to the need for a change of use of areas, resolution of internal conflicts and greater supervision by the managing bodies. The cartographic elaborations and data surveyed can be used as subsidies to the Conservation Unit planning and management, aiming to reach the goals set for the category.

Keywords: Atlantic Forest; Conservation Unit; Environmental Zoning.

\section{Introdução}

No Brasil, a política de áreas protegidas teve início na primeira metade do século XX, com a criação do primeiro Parque, o de Itatiaia, que materializou, assim, reivindicações, debates e mobilizações que atravessaram séculos. De um lado ambientalistas e populações tradicionais, com o interesse de proteger o meio natural, e do outro, setores ligados ao agronegócio, com interesses em explorar os ecossistemas e expandir as áreas produtivas. Essa conjuntura conflituosa ainda caracteriza as discussões sobre a implantação de áreas protegidas no país.

No processo histórico de degradação ambiental, a Mata Atlântica foi um dos biomas mais ameaçados, e mesmo sendo uma das áreas com maior biodiversidade do mundo, é um dos biomas mais afetadas pela ação antrópica na atualidade, sendo considerado um hostspot mundial. O bioma se estende por quase toda a costa atlântica brasileira, tendo sido explorado pelos colonizadores europeus e durante os ciclos econômicos que se sucederam. Mais de metade da sua cobertura natural foi destruída, originando fragmentos de diversas formas e tamanhos, sujeitos a perturbações diferenciadas ao longo do território.

Em decorrência dos fatos colocados, questiona-se como proteger os fragmentos de Mata Atlântica? A resposta pode estar na criação de Unidades de Conservação firmadas no Sistema Nacional de Unidades de Conservação - SNUC, criado através da Lei 9.985 de 2000. Entretanto, mesmo com o SNUC, muitas áreas destinadas à proteção existem apenas no papel, não chegando na realidade a ser implantadas. Muitas delas, mesmo com vários anos de criação, não possuem Plano de Manejo, tampouco foi realizado o Zoneamento Ambiental.

No estado da Paraíba, dentre as Unidades de Conservação do bioma Mata Atlântica, o Parque Estadual Mata do Pau Ferro se evidencia como um dos fragmentos mais representativos. Situado no município de Areia, na unidade geoambiental do Planalto 
da Borborema, o fragmento encontra-se em condição de Brejo de Altitude e se evidencia como Refúgio, segundo Ab'Sáber (2003). Mesmo com tais singularidades, o Parque apresenta dificuldades de gestão, como por exemplo a implementação do Plano de Manejo, conforme preconiza o artigo 27 do SNUC:

\begin{abstract}
Documento técnico mediante o qual, com fundamento nos objetivos gerais de uma Unidade de Conservação, se estabelece o seu zoneamento e as normas que devem presidir o uso da área e o manejo dos recursos naturais, inclusive a implantação das estruturas físicas necessárias à gestão da Unidade de Conservação (Brasil, 2000, art. $\left.2^{\circ}, \mathrm{XVII}\right)$.
\end{abstract}

O Parque não possui Plano de Manejo implementado e por isso não dispõe de zoneamento de suas áreas. Diante do exposto, o presente artigo apresenta uma proposta de Zoneamento Ambiental para o Parque Estadual Mata do Pau Ferro, com vista a fornecer subsídios para a gestão da Unidade de Conservação.

\title{
1. Unidades de Conservação: reflexões teóricas
}

Segundo Dorst (1973) as discussões sobre a criação de reservas naturais têm início nos Estados Unidos, desencadeadas a partir do contexto de devastação das florestas que se evidenciou no século XIX. De acordo com o autor, o cenário que se apresentava levou o Congresso americano a ceder o vale de Yosemite e Mariposa Grove ao Estado da Califórnia, em 1864, para o estabelecimento de uma Reserva Natural, visando proteger as sequoias e manter estas áreas em estado natural para uso do público. Anos depois é criado o Parque Nacional de Yellowstone, em março de 1872, o primeiro no mundo, constituindo um marco histórico na criação de áreas protegidas. $O$ estabelecimento do parque foi influenciado por ideias de preservação, com o intuito de manter remanescentes protegidos das perturbações diretas do homem (Castro Júnior et al., 2009).

Na América do Sul diversos parques foram criados, entretanto, por ter apresentado um quadro de degradação tardio, a proteção da natureza não teve o mesmo caráter de urgência que se evidenciou nos Estados Unidos. O Parque Nacional de Itatiaia, criado em 1937 durante o Governo de Getúlio Vargas, sendo a primeira área protegida do Brasil, marcou o início da política de áreas protegidas no país, pois concretizou as reinvindicações, mobilizações e discussões que já haviam sido iniciadas durante a colônia (Medeiros, 2006; Castro Júnior et al., 2009). Nas décadas seguintes, com o apoio de mecanismos legais, novas categorias de áreas protegidas foram estabelecidas. Entretanto, é apenas no despontar do século XXI que ocorre uma integração entre as esferas municipal, estadual e federal no que diz respeito à gestão das áreas protegidas no país, que até então ocorria de forma desvinculada.

A criação do Sistema Nacional de Unidades de Conservação - SNUC, através da Lei 9.985 de 2000, estabeleceu um novo panorama acerca das áreas protegidas no Brasil. A Lei do SNUC possibilitou a integração entre as esferas para a gestão das Unidades de Conservação distribuídas no país e apontou a obrigatoriedade de formação de conselhos gestores para as Unidades de Conservação, contando com a participação 
de diversos agentes, como órgãos públicos, setores privados, populações tradicionais, proprietários de terras, comunidade cientifica, entre outros.

O SNUC é composto por 12 categorias de Unidades de Conservação, distribuídas em dois grandes grupos: o de Proteção Integral, que tem por objetivo a preservação da natureza, sendo admitido apenas o uso indireto dos recursos naturais; e o grupo de Uso Sustentável, com o objetivo básico de compatibilizar a conservação da natureza com o uso sustentável de parte dos recursos naturais. O grupo de Proteção Integral é composto por cinco categorias: Estação Ecológica; Reserva Biológica; Parque Nacional; Monumento Natural; e Refúgio de Vida Silvestre. Já o grupo de Uso Sustentável está composto por 7 categorias: Área de Proteção Ambiental; Área de Relevante Interesse Ecológico; Floresta Nacional; Reserva Extrativista; Reserva de Fauna; Reserva de Desenvolvimento Sustentável; e Reserva Particular do Patrimônio Natural.

No grupo de Proteção Integral, a categoria Parque é a mais representativa, tanto em número quanto em área abrangida, em relação às outras categorias que integram o grupo. Segundo BRASIL (2019a), existem nesta categoria 74 parques federais, 218 estaduais e 163 municipais, totalizando 455 Unidades de Conservação, abrangendo uma área total de $363.545 \mathrm{~km}^{2}$. Segundo o SNUC:

\footnotetext{
O Parque Nacional tem como objetivo básico a preservação de ecossistemas naturais de grande relevância ecológica e beleza cênica, possibilitando a realização de pesquisas científicas e o desenvolvimento de atividades de educação e interpretação ambiental, de recreação em contato com a natureza e de turismo ecológico (Brasil, 2000, art. 11).
}

Conforme visto, os parques buscam conciliar a preservação dos componentes bióticos e abióticos, com a atividade de pesquisa e visitação para fins de recreação, educação ambiental e ecoturismo, permitindo o desenvolvendo da conscientização ambiental e apreciação da beleza cênica nestes espaços. Cabe ressaltar que as atividades desenvolvidas nos parques estão sujeitas a normas e critérios, que visam cumprir ao mesmo tempo a função de categoria de proteção integral e espaço público de visitação, e estas são fiscalizadas pelos agentes envolvidos no manejo e gestão das Unidades de Conservação.

Dentre os instrumentos utilizados para gestão das unidades de conservação, o Plano de Manejo representa o principal deles. O Plano de Manejo resulta do planejamento, e a sua elaboração inclui estudos do meio biótico, abiótico e social, possuindo caráter multidisciplinar, com características variáveis conforme as particularidades de cada unidade, uma vez que visa orientar todas as atividades desenvolvidas no território da Unidade de Conservação. Sua elaboração deve contar com a participação de todos os agentes envolvidos com a Unidade de Conservação, como prefeituras e órgãos gestores.

Tratando-se do Plano de Manejo, o Zoneamento representa um dos seus principais componentes, pois estabelece as zonas com diferentes graus de proteção, alteração 
e formas de uso na Unidade de Conservação. Para Guerra e Lopes (2009) o Zoneamento é uma ferramenta de fundamental importância para o planejamento nas áreas protegidas. O zoneamento representa um instrumento de ordenamento territorial, utilizado com a finalidade de melhorar os resultados na gestão, tendo em vista que aponta diferentes usos para cada zona, perseguindo os objetivos que levaram ao seu estabelecimento, além de permitir um melhor desenvolvimento das atividades previstas para a unidade de conservação (IBAMA, 2002). O SNUC define o zoneamento como sendo a:

\begin{abstract}
Definição de setores ou zonas em uma unidade de conservação com objetivos de manejo e normas específicos, com o propósito de proporcionar os meios e as condições para que todos os objetivos da unidade possam ser alcançados de forma harmônica e eficaz (Brasil, 2000a, art $\left.2^{\circ}, X V I\right)$.
\end{abstract}

Nesse sentido, é visto que o Zoneamento, como ferramenta de gestão da unidade, surge a partir da conciliação entre as dimensões físicas, biológicas e socioeconômicas. Para Françoso et al. (2011), o zoneamento deve se basear nas melhores informações disponíveis sobre os componentes naturais, biodiversidade, potencialidades e fragilidades. Para isso, é fundamental o uso de Sistemas de Informações Geográficas (SIG) e Sensoriamento Remoto, como subsídios para a delimitação das zonas e definição de estratégias com vista a promover a conservação das áreas e cumprir os objetivos definidos pela categoria da Unidade de Conservação.

\title{
2. Metodologia
}

\section{1. Área de estudo}

O município de Areia está localizado no estado da Paraíba, na mesorregião do Agreste Paraibano e na microrregião do Brejo Paraibano (Figura 1). Possui uma área territorial de $266,596 \mathrm{~km}^{2}$, apresentando uma população de 23.829 habitantes no ano de 2010 e tendo sua população estimada em 22.819 habitantes para o ano de 2019 (IBGE, 2019). A economia tem seu maior expoente nos setores agrícola, pecuário e turístico (IBGE, 2008).

O território municipal está inserido nos domínios da bacia hidrográfica do rio Mamanguape, apresenta rios intermitentes e o padrão de drenagem é dendrítico. $O$ relevo é predominantemente suave-ondulado e ondulado, com solos profundos e mediamente férteis. Segundo a classificação climática de Köppen o clima municipal é do tipo As, quente e úmido com chuvas de outono e inverno (Paraíba, 1985). 


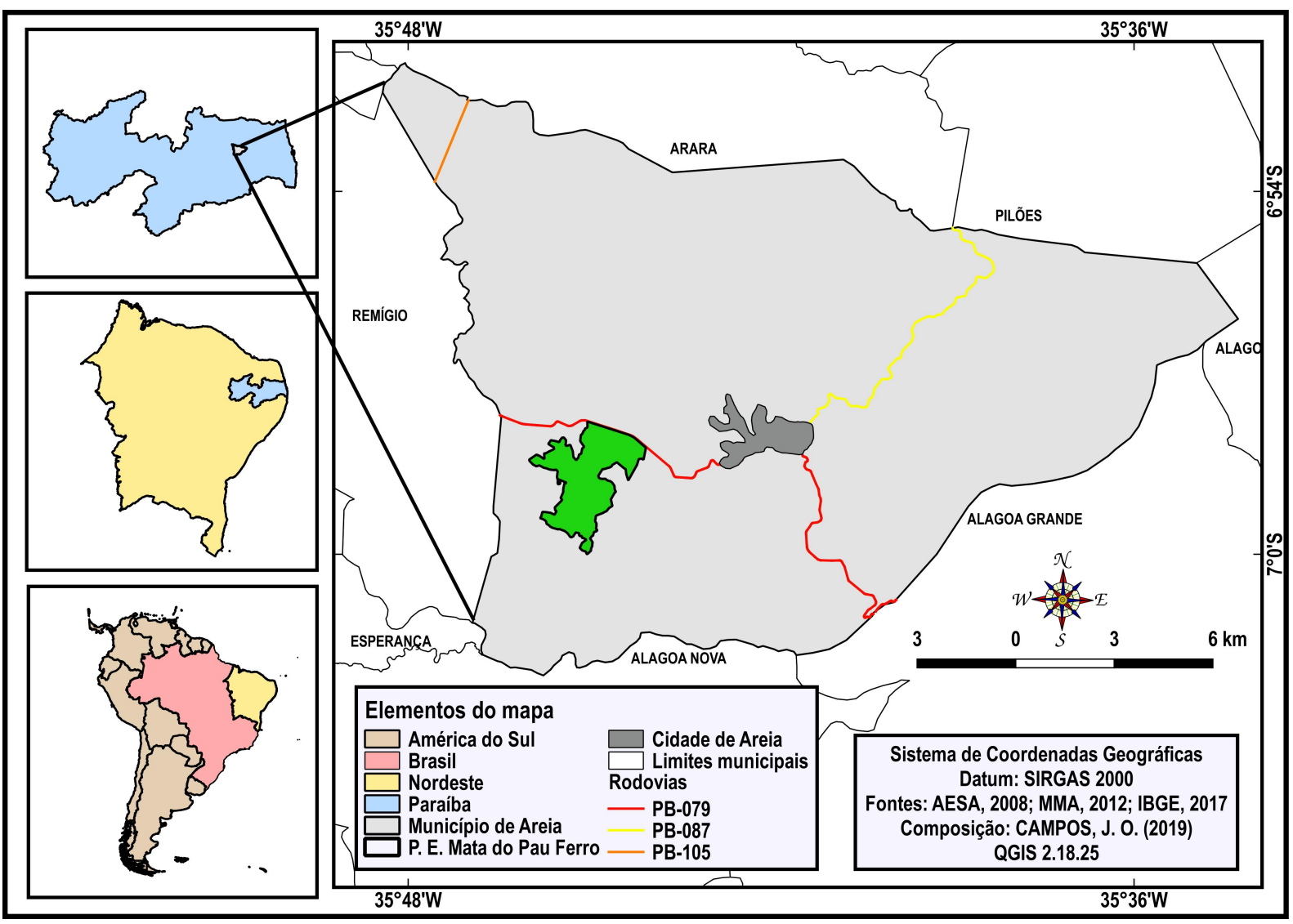

Figura 1: Localização do município de Areia no estado da Paraíba

O Parque Estadual Mata do Pau Ferro é uma unidade de conservação pertencente ao grupo de Proteção Integral do Sistema Nacional de Unidades de Conservação. Está localizada na comunidade Chã do Jardim, zona rural do município de Areia, estado da Paraíba e é administrada pela Superintendência de Administração do Meio Ambiente - SUDEMA (Figura 2). De acordo com a SUDEMA (2018) o estado da Paraíba possui 43 unidades de conservação, 6 federais, 12 municipais, 10 particulares e 15 administradas pela autarquia. Dentre as 15 unidades administradas pela autarquia, 9 exigem Proteção Integral.

A unidade foi criada em 19 de outubro de 1992, como Reserva Ecológica da Mata do Pau Ferro, através do Decreto Estadual n 14.832, e em 2005, através do Decreto Estadual $n^{\circ} 26.098$, de 04 de agosto de 2005, a Reserva foi recategorizada para a categoria Parque de domínio estadual, passando então, a constituir o Parque Estadual Mata do Pau Ferro (Paraíba, 2005). O Parque possui uma área de 607,96 hectares e situa-se a oeste da cidade de Areia, distando $5 \mathrm{~km}$.

O Parque abriga um remanescente de Mata Atlântica em condição de Brejo de Altitude, configurando-se como um Refúgio Florestal, propiciado pelas características físico-naturais dos Brejos de Altitude que pontilham as áreas de Caatinga no Nordeste (Ab'sáber, 1992). A unidade está situada na microbacia hidrográfica da barragem Vaca Brava e comporta o reservatório em seu interior. Em 1992, quando foi criada a reserva, entre seus objetivos estava a proteção da vegetação e dos recursos hídricos na microbacia (Paraíba, 1992). 


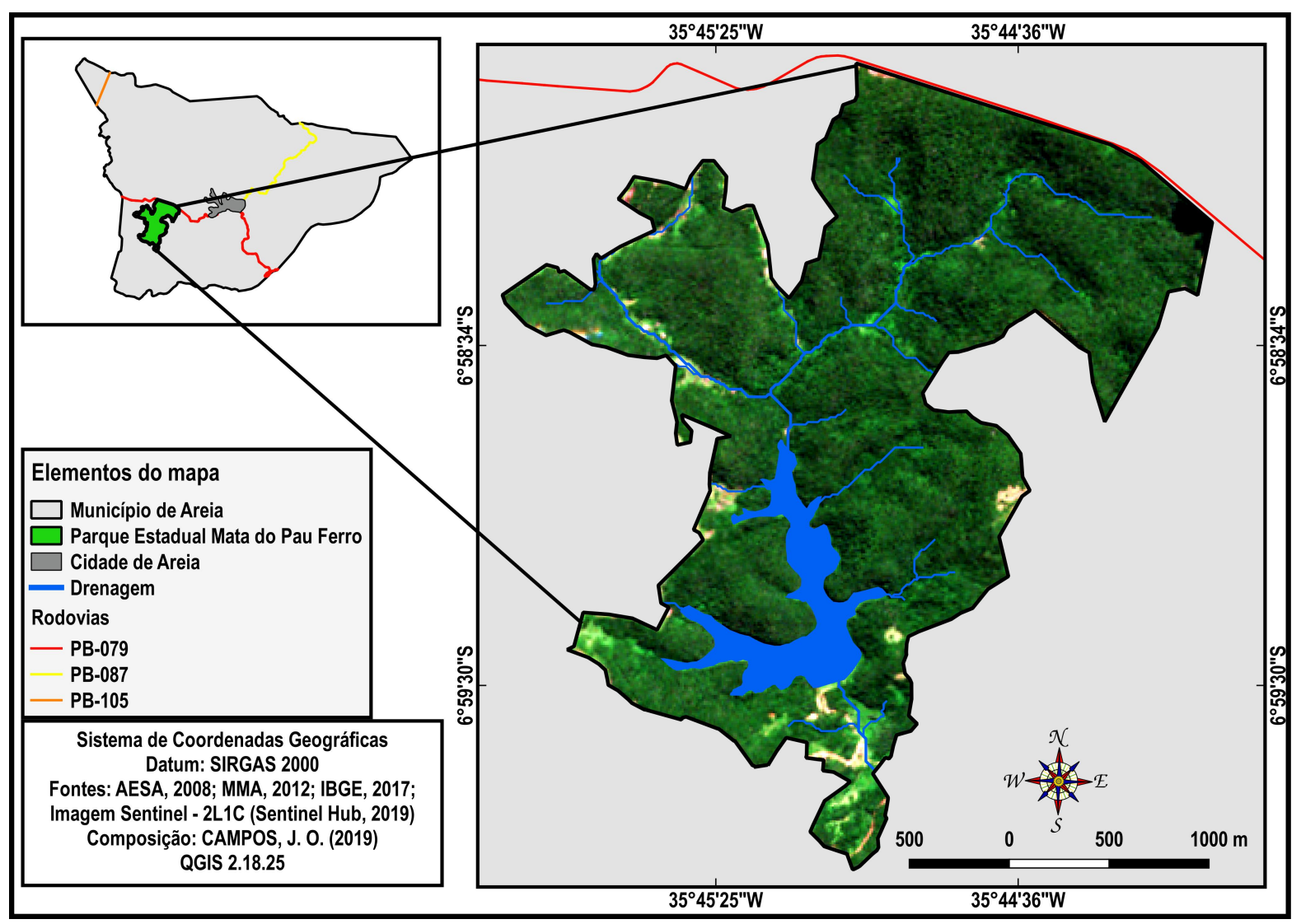

Figura 2: Localização do Parque Estadual Mata do Pau Ferro no município de Areia

\subsection{Procedimentos metodológicos}

A construção do Zoneamento Ambiental foi realizada durante o ano de 2019 e foi dividida nas seguintes etapas:

1. Levantamento bibliográfico acerca da temática abordada, com ênfase na política de áreas protegidas no Brasil, bioma Mata Atlântica, gestão da biodiversidade, refúgios florestais, plano de manejo e zoneamento ambiental em unidades de conservação. O levantamento possibilitou a construção da revisão de literatura deste trabalho e embasou as discussões que se seguem.

2. Aquisição de imagem orbital para elaboração do mapa de cobertura do solo e mapeamento das zonas no Parque Estadual Mata do Pau Ferro.

3. Saídas de campo para mapeamento das trilhas, dos pontos turísticos, coleta de amostras espectrais para classificação supervisionadas das imagens orbitais e registro fotográfico.

4. Aquisição de dados secundários e levantamento de dados primários para elaboração dos seguintes mapas: domínios geológico-ambientais; hipsometria; declividade; solos; Áreas de Preservação Permanente; cobertura do solo; trilhas; Áreas de uso conflitante; pontos de referência; e por fim, elaboração do produto 
final, representado pelo mapa de zoneamento ambiental da Unidade de Conservação.

5. Extração das métricas da paisagem e posterior elaboração de tabelas para análise e representação das áreas.

\subsubsection{Materiais e instrumentos}

Para realização do Zoneamento Ambiental foram utilizados os seguintes materiais:

1. Uma imagem orbital do sensor MSI (Multi-Spectral Instrument), integrante do Satélite Sentinel - 2B, disponibilizada gratuitamente pela ESA - European Space Agency, através da plataforma Sentinel Hub, a data de aquisição da imagem consta no Quadro 1. A imagem foi utilizada para elaboração dos mapas referentes ao território da Unidade de Conservação.

Quadro 1: Dados das imagens de satélite utilizadas

\begin{tabular}{|l|l|l|l|l|l|l|}
\hline SATÉLITE & SENSOR & NÍVEL & RESOLUÇÃO & MGRS & AQUISIÇÃO & FONTE \\
\hline Sentinel-2B & MSI & $1 \mathrm{C}$ & 10 e $20 \mathrm{~m}$ & $25 \mathrm{MBN}$ & $02 / 06 / 2019$ & Sentinel Hub/ ESA (2019) \\
\hline
\end{tabular}

2. Imagem de radar do sensor PALSAR (Phased Array L-band Synthetic Aperture Radar), integrante do satélite ALOS, com Modelo Digital de Terreno - MDE, em resolução de 12,5m, de 07/11/2009, disponibilizadas gratuitamente através da ASF - Alaska Sattelite Facility / NASA.

3. Base cartográfica da América do Sul, Brasil, Nordeste, Paraíba e do município de Areia, no formato shapefile, adquiridas gratuitamente no Portal de Mapas do IBGE.

4. Polígono no formato shapefile da Unidade de Conservação Parque Estadual Mata do Pau Ferro, disponibilizado pelo Ministério do Meio Ambiente através do Cadastro Nacional de Unidades de Conservação - CNUC.

5. Aparelho de GPS (Global Positioning System) modelo Etrex Garmin Vista.

6. Aplicativo Android GPS Essentials versão 4.4.27, adquirido gratuitamente na Play Store.

7. Fita métrica de $50 \mathrm{~m}$.

Para o processamento dos dados e elaboração dos mapas foi utilizado o Software livre QGIS na versão 2.18.25. Os mapas foram elaborados a partir do polígono disponibilizado pelo Ministério do Meio Ambiente através do Cadastro Nacional de Unidades de Conservação, que apresenta uma área de 607,96 hectares.

\subsubsection{Etapa de campo}

Os trabalhos de campo foram realizados nos dias 10, 11 e 29 de agosto de 2019. A primeira etapa dos trabalhados de campo consistiu em percorrer todas as trilhas com 
auxílio de um dos guias do Parque: as trilhas oficiais mantidas pelos guias, as trilhas abertas por moradores locais e as estradas instaladas antes da implementação da Unidade de Conservação.

\subsubsection{Elaboração do mapa de Zoneamento Ambiental}

O zoneamento foi construído tomando como base as condições ambientais apresentadas através dos mapas, os usos, a necessidade de proteção das áreas e os critérios propostos pelo IBAMA (2002): grau de conservação da vegetação; variabilidade ambiental; representatividade; áreas de transição; suscetibilidade ambiental; potencial de visitação; potencial para conscientização ambiental; presença de infraestrutura; uso conflitante; e presença de população.

Foram, então, estabelecidas as seguintes zonas: Zona Intangível; Zona Primitiva; Zona de Uso Extensivo; Zona de Recuperação; Zona de Uso Conflitante; Zona de Ocupação Temporária; e Zona de Uso Especial.

\section{Resultados e discussões}

Os resultados que se seguem apresentam a série de mapas elaborados para o estabelecimento do Zoneamento Ambiental. Foi dada ênfase às condições ambientais retratadas através dos mapas e à necessidade de proteção demandada pelas áreas. Por fim, é apresentado o mapa de Zoneamento Ambiental, seguido da descrição das zonas, seus usos e permissões. O Parque Estadual Mata do Pau Ferro não possui Plano de Manejo implementado, que ainda se encontra em construção. Dessa forma, a unidade não dispõe de zoneamento e zona de amortecimento, que constituem instrumentos fundamentais para a gestão da área. Junto a isso, soma-se a falta de recursos e pessoal dos órgãos gestores para uma efetiva fiscalização e gestão da unidade. Em decorrência disso, o Parque apresenta diversos conflitos no que diz respeito à ocupação das terras e uso dos recursos naturais disponíveis.

\subsection{Domínios geológicos}

O substrato litológico do Parque Estadual Mata do Pau Ferro enquadra-se em dois domínios geológicos do estado da Paraíba (Figura 3). O primeiro abrange a porção mais ao norte do Parque, que possui natureza metamórfica, e conforme Pfaltzgraff et al. (2016) apresenta as seguintes características: alteração irregular dos terrenos; solos e litologia de alta e baixa depuração e retenção de agentes poluentes; e litologias pouco individualizadas e de grande variação vertical e lateral.

O segundo domínio abrange predominantemente a porção sul do Parque. Também de natureza metamórfica, apresenta de acordo com o Pfaltzgraff et al. (2016) as seguintes características: litologia de alteração irregular com predominância de gnaisses ortoderivados; rochas de elevada resistência ao intemperismo físico; rochas com alteração predominante para solos argilo-síltico-arenosos; ocorrência de solos residuais de elevada pedogênese pouco erosivos; e ocorrência de solos pouco desenvolvidos bastante erosivos, de fácil compactação e impermeabilização. 
O Mapa representando na Figura 3 é um recorte do Mapa da Geodiversidade da Paraíba, que apresenta a escala de 1:500.000. Dessa forma, é possível que ocorram generalizações em relação à delimitação dos domínios geológicos do Parque, e estes não correspondam à realidade em determinadas porções.

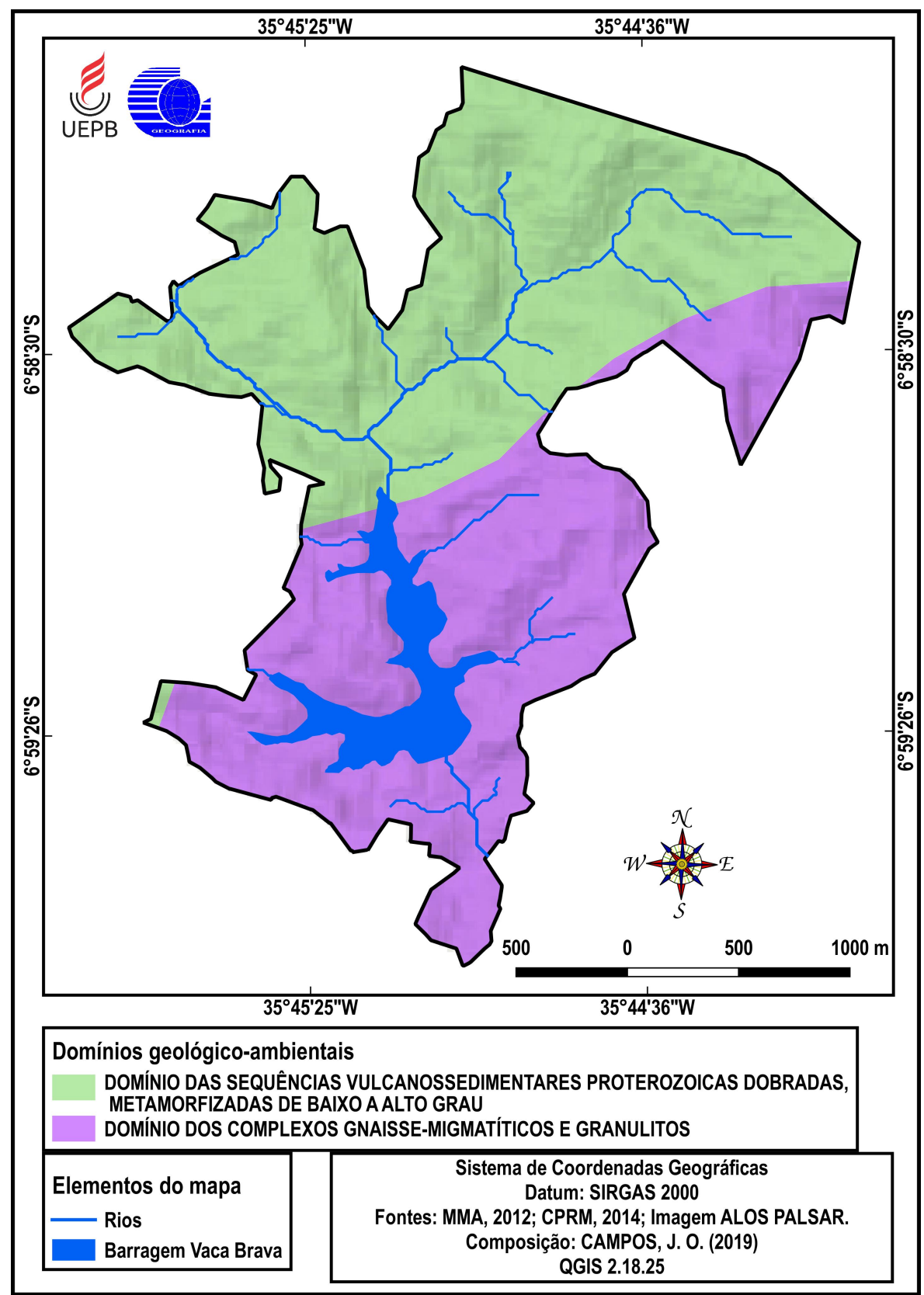

Figura 3: Domínios geológicos do Parque Estadual Mata do Pau Ferro

Relativamente à vulnerabilidade dos solos, em ambos os domínios geológicos tais áreas necessitam estar localizadas em zonas de maior proteção, visando assim preservar seus atributos físico-naturais, e reduzir quadros/processos de erosão. 


\subsection{Hipsometria}

Conforme é verificado na Figura 4, a hipsometria do Parque é variada, apresentando acentuados gradientes de altitude nos pontos mais elevados. As áreas de maior altitude localizam-se na porção norte do Parque, e apresentam altitudes entre $600 \mathrm{e}$ 633 metros, sendo esta última a cota máxima do terreno.

A maior parte das nascentes está circundada por altitudes que variam de 540 a 600 metros. Em vista do gradiente entre as cotas, tais áreas necessitam estar inseridas em zonas de maior proteção, no intuito de evitar a intensificação de processos erosivos. Além disso, se faz necessária atenção com a manutenção da cobertura vegetal, para promover a estabilidade do terreno, principalmente nas áreas de transição de cotas.

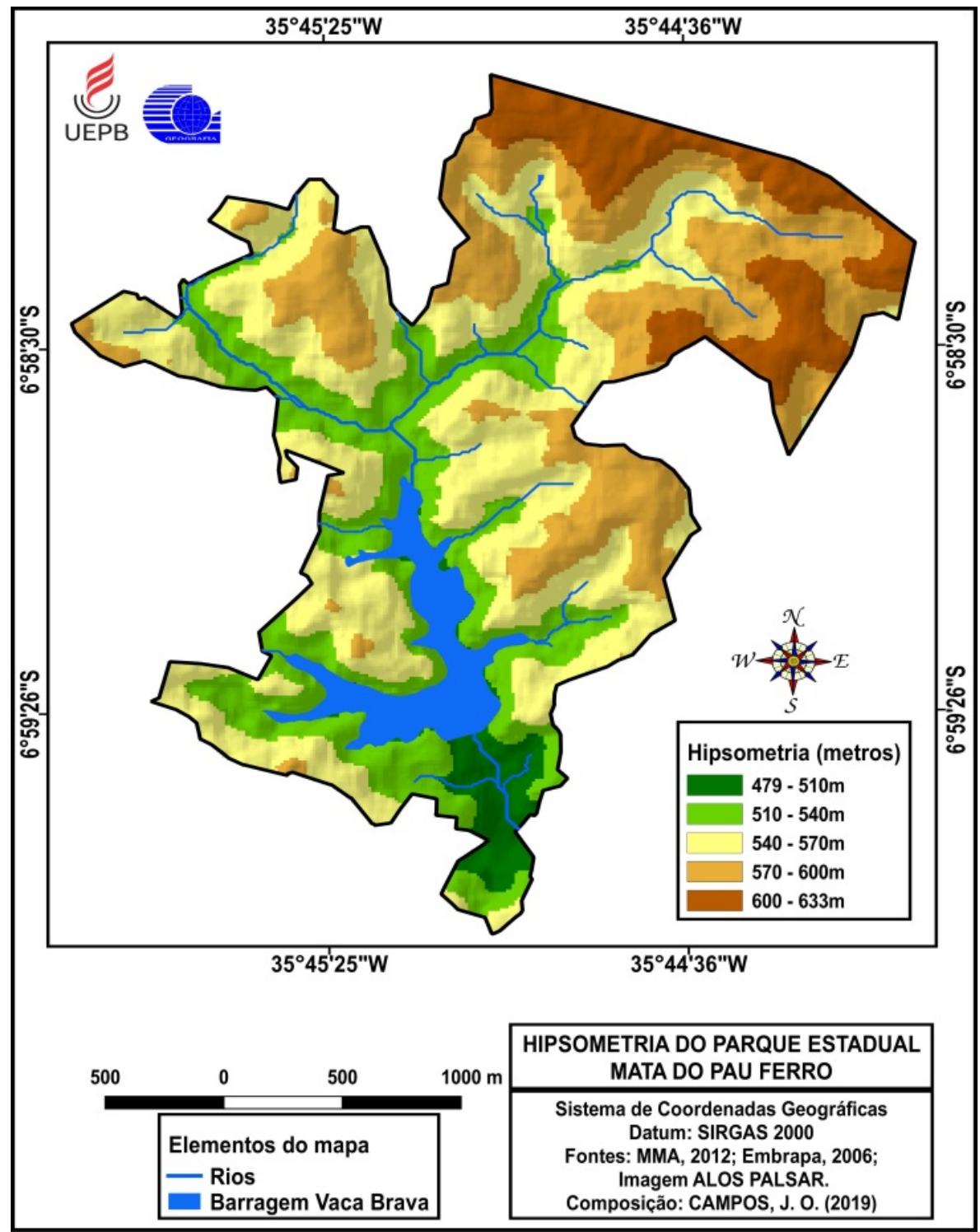

Figura 4: Hipsometria do Parque Estadual Mata do Pau Ferro

Altitudes mais baixas predominam na porção central e sul do Parque, onde se localiza a barragem Vaca Brava, área de menor cota, a saber, 479 metros. O reservatório 
hídrico está circundado pela cota de 510 a 540 metros, que ocorre desde as áreas mais rebaixadas ao norte até os terrenos a sudeste do reservatório. De forma geral, as superfícies de transição e com gradiente acentuado foram consideradas prioritárias a serem inseridas em zonas de maior proteção.

\subsection{Declividade}

Em relação à declividade, os terrenos de maior declive ocorrem nas faixas de transição entre as cotas altimétricas, e acentuam-se conforme o gradiente de altitude, sendo exemplos áreas que marginam as nascentes na porção norte do Parque (Figura $5)$.

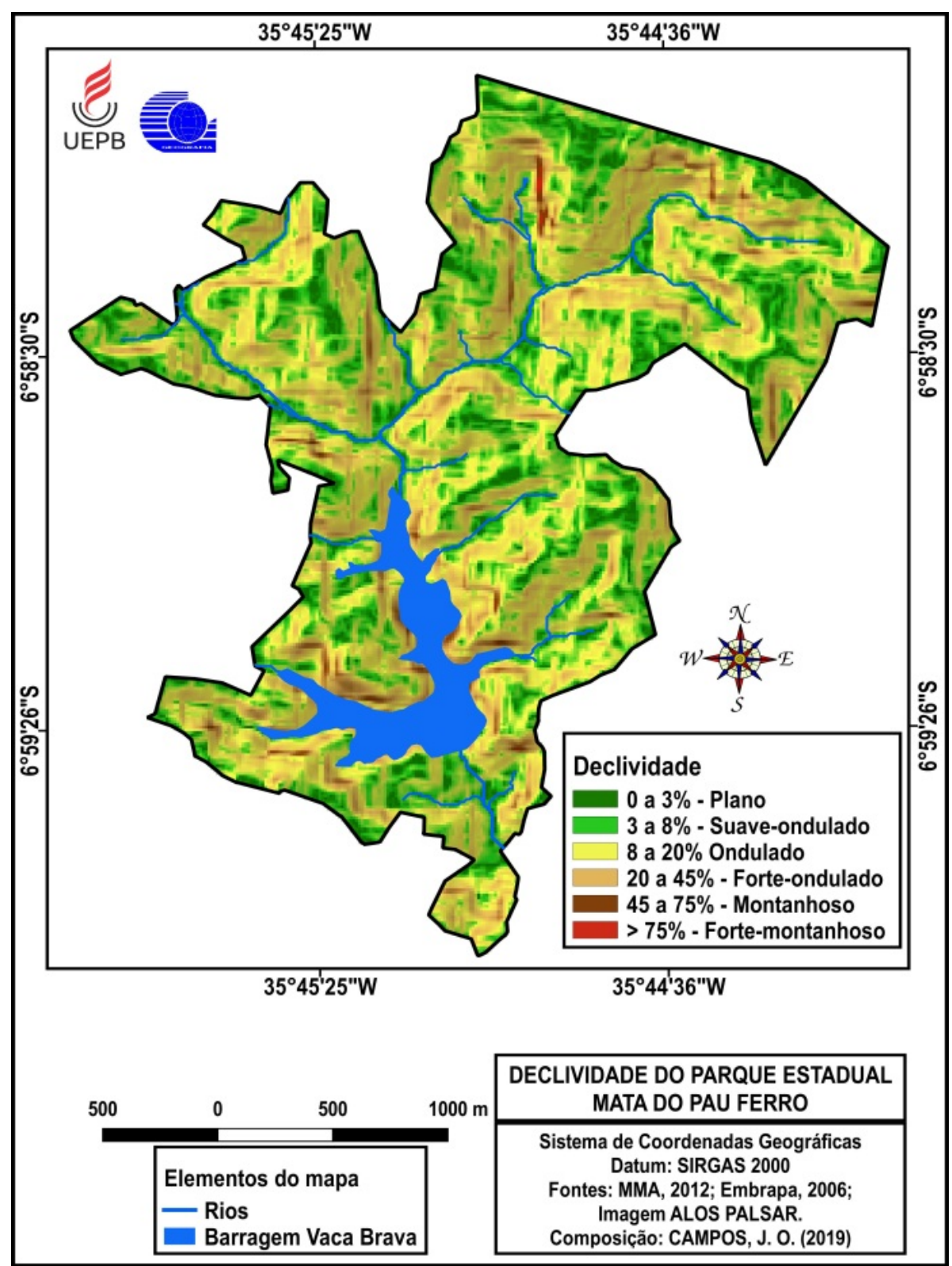

Figura 5: Declividade do Parque Estadual Mata do Pau Ferro 
No topo das elevações predominam declividades entre 0 e $8 \%$, representando assim terrenos menos susceptíveis à erosão. Devido a tais condições, estas áreas podem ser inseridas em zonas de menor proteção, possibilitando também usos diversificados. As superfícies de maior declive encontram-se nas vertentes dos rios que nascem na porção norte, e em alguns pontos as declividades chegam próximas a $45^{\circ}$. Declives intermediários variando de 20 a $75 \%$ ocorrem no terreno circundante à barragem de Vaca Brava, em virtude do gradiente de altitude que se forma na área. O relevo que circunda o reservatório apresenta valores entre 540 e 570 metros de altitude, já o vale onde se assenta corpo d'água apresenta altitudes variando entre 479 e 510 metros. Tal condição favorece a instalação de declividades mais acentuadas nas superfícies de transição entre as cotas, em virtude das diferenças altimétricas.

Em termos de zoneamento, as faixas de maior declive devem ser inseridas em zonas de maior proteção, em função da vulnerabilidade e susceptibilidade à erosão dos solos. Se faz necessário, também, o monitoramento destas áreas e a permanente manutenção da cobertura vegetal, para fins de preservação.

O Parque não apresenta encostas com declives superiores a $45^{\circ}$, por isso não foi possível delimitar Áreas de Preservação Permanente (APP'S) e declividade, conforme dispõe a Lei de Proteção da Vegetação Nativa - LPVN, n 12.651, de 25 de maio de 2012, conhecida popularmente como Novo Código Florestal. De acordo com a Lei, as APPs têm como objetivo a preservação dos recursos hídricos, da paisagem e da estabilidade geológica, proteção do solo e da biodiversidade (Brasil, 2012).

\subsection{Solos}

O Parque Estadual Mata do Pau Ferro apresenta três classes de solos, conforme o Sistema Brasileiro de Classificação de Solos - SiBCS (Santos et al., 2018): Argissolos, que compreendem solos de avançada evolução pedogenética, incompleta atuação do processo de ferratilização, presença do horizonte B textural, sendo estes solos forte a imperfeitamente drenados; Luvissolos, que compreendem solos minerais, e que apresentam o horizonte $B$ textural imediatamente abaixo de um horizonte $A$ ou $E$, argila de alta atividade e elevada saturação por bases, variando de bem a imperfeitamente drenados, sendo geralmente pouco profundos; e os Neossolos, que compreende solos pouco evoluídos, constituídos por material mineral ou orgânico, com menos de $20 \mathrm{~cm}$ de espessura, não apresentando nenhum tipo de horizonte $\mathrm{B}$ diagnóstico.

Como a fonte usada como referência para descrever os solos do local é generalizado, não foi possível apresentar a localização específica das classes de solo. Recomendase o desenvolvimento de pesquisas com maior detalhe dos tipos de solo. Mesmo assim, considerando a generalização do recorte, depreende-se que as áreas mais declivosas devem estar inseridas em zonas de maior proteção, em vista que se inseridas em zonas de menor proteção, o uso intensivo destas pode acarretar a intensificação de processos erosivos nos solos. Nesse sentido, considerando as características gerais dos solos, a declividade e o relevo, as zonas de menor proteção 
e maior uso devem se localizar nas superfícies mais aplainadas por ser mais apropriado para o desenvolvimento de atividades.

\subsection{Delimitação das Áreas de Preservação Permanente - APPs}

As APPs hídricas do Parque foram delimitadas em conformidade com o que dispõe a legislação vigente. Foram estabelecidas APPs para as nascentes, afluentes do rio Vaca Brava e para o reservatório artificial rural, mostrando a Figura 6 a sua delimitação. Foram mapeadas 14 nascentes, posteriormente circundadas com APPs de 50m, respectivamente, conforme disposto no Novo Código Florestal (Brasil, 2012). Ao longo dos rios foram estabelecidas APPs de 50 e 30 metros, respectivamente, em conformidade com a largura do rio.

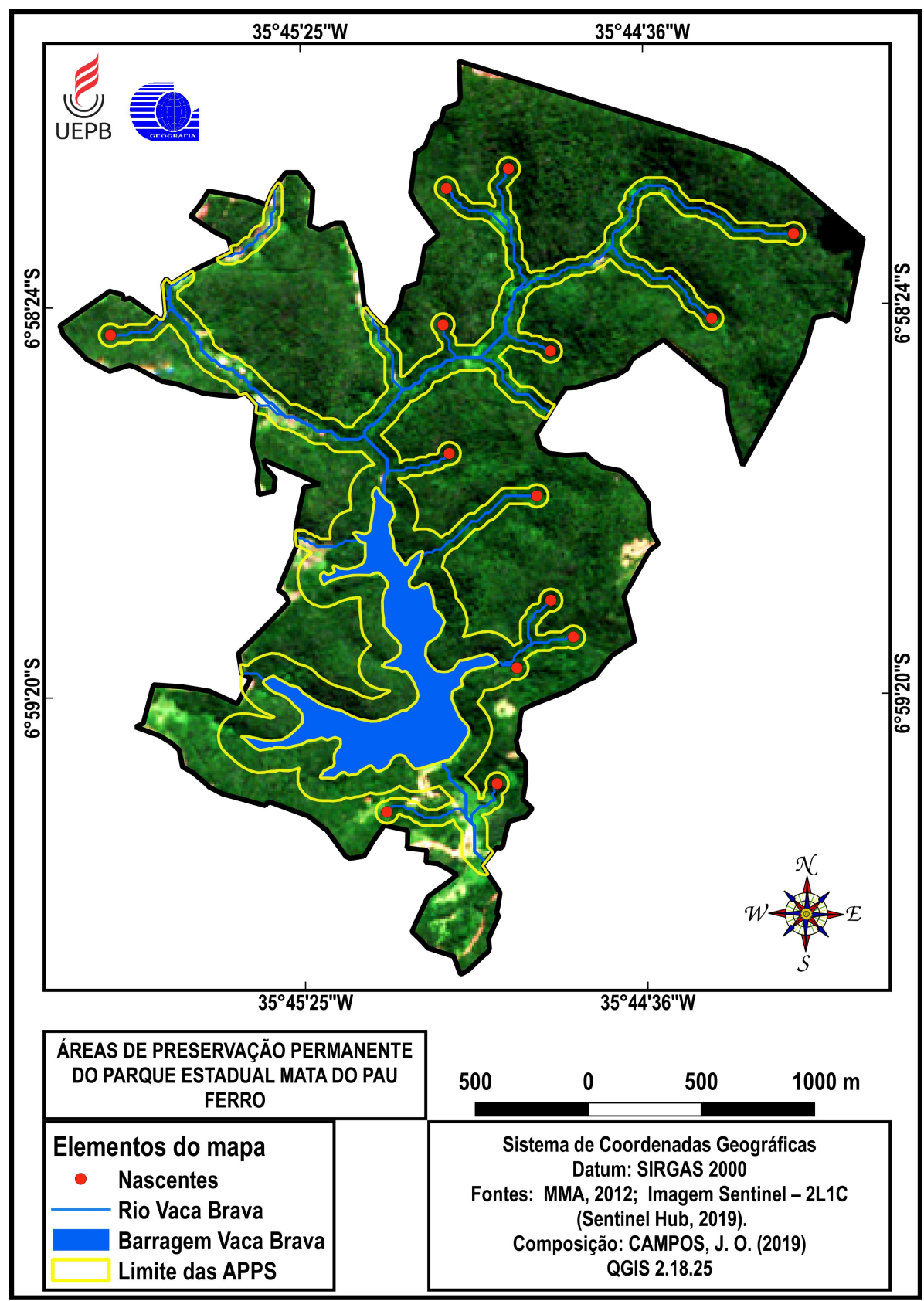

Figura 6: Áreas de Preservação Permanente do Parque Estadual Mata do Pau Ferro 
Para a barragem Vaca Brava foi estabelecida uma APP com limite de 100m, embora, as APPS de reservatórios artificiais localizados na zona rural devam ser estabelecidas no licenciamento ambiental, observado o limite mínimo de $30 \mathrm{~m}$ e máximo de $100 \mathrm{~m}$ (Brasil, 2012). Optou-se por estabelecer o limite máximo de $100 \mathrm{~m}$, para maior proteção e em vista que o reservatório foi construído antes da implantação da Unidade de Conservação.

Durante os trabalhos de campo foi verificado que a maior parte das áreas onde se encontram as nascentes foi utilizada para fins agrícolas e pecuários, de forma que nestes locais ainda é possível encontrar indicativos destes. Foram encontradas nascentes circundadas por plantações de bananeiras e também por plantações de capim, sendo o capim utilizado para a manutenção da atividade pecuária no interior do Parque. Foi observado, durante os trabalhos de campo, que algumas das nascentes foram encanadas e tiveram o seu fluxo canalizado através de tubos para pontos mais rebaixados do terreno, provavelmente no período em que as terras do Parque ainda pertenciam aos antigos engenhos da região.

A preservação das nascentes do Parque se mostra de fundamental importância para a manutenção do sistema hídrico da barragem Vaca Brava, tendo em vista que 12 nascentes aportam água para o reservatório. Vaca Brava, junto com o reservatório Saulo Maia, são os dois principais mananciais do município, responsáveis por abastecer Areia e áreas vizinhas.

As APPs atuam na proteção e manutenção do sistema hídrico do Parque, e a intervenção humana desornada sobre estas áreas pode resultar na contaminação das águas por agroquímicos, produção de sedimentos e assoreamento dos rios e do manancial Vaca Brava. Em uma visão sistêmica, é necessária também a delimitação e fiscalização ambiental sobre as demais APPs da microbacia Vaca Brava, tendo em conta que a maior parte das nascentes se situa fora dos domínios do Parque, nos terrenos a oeste.

Do mesmo modo, a intervenção humana desenfreada sobre estas APPs ao longo da microbacia pode promover a produção de sedimentos, intensificação dos processos de erosão e contaminação das águas dos rios. Como será visto adiante, a microbacia está coberta predominantemente por pastagens, o que indica a presença de atividade pecuária na maior parte da bacia. Nesse sentido, as águas vindas dos terrenos externos podem apresentar qualidade inferior às do Parque, em decorrência das atividades antrópicas desenvolvidas ao longo da bacia.

A Tabela 1 mostra a área das respectivas APPs e o percentual de área coberta em relação a área total do Parque.

As APPs cobrem um total 138,02 hectares, equivalente a $22,70 \%$ da área total do Parque, constituindo barreiras/filtros que atuam na proteção e manutenção dos recursos hídricos. Necessitam, assim, de intensa fiscalização sobre as atividades que se desenvolvem nelas e em terrenos próximos. Na delimitação das APPs dos rios, algumas ultrapassaram os limites do Parque. Em vista disso, não foram consideradas 
no somatório das áreas, embora também façam parte dos rios. Para os fins do zoneamento foram consideradas apenas as que se encontram na Unidade de Conservação.

Tabela 1: Área das APPS e percentual de área coberta

\begin{tabular}{l|r|r}
\hline Áreas de Preservação Permanente - APPS & Área (ha) & \multicolumn{1}{|c}{ Percentual (\%) } \\
\hline Nascentes & 10,82 & $\mathbf{1 , 7 8}$ \\
\hline Rios & 62,10 & 10,21 \\
\hline Barragem Vaca Brava & 65,10 & 10,71 \\
\hline Total & $\mathbf{1 3 8 , 0 2}$ & $\mathbf{2 2 , 7 0}$ \\
\hline Área da UC & $\mathbf{6 0 7 , 9 6}$ & \multicolumn{2}{|c}{} \\
\hline
\end{tabular}

Como visto na Tabela 1, a APP da barragem Vaca Brava apresenta o maior percentual em relação à área total do Parque, já as APPs de nascentes cobrem um percentual de $1,78 \%$ da Unidade de Conservação. As APPs visam a preservação dos recursos hídricos, a paisagem, a estabilidade geológica, o solo e a biodiversidade (Brasil, 2012). Nesse sentido, estas áreas têm prioridade no enquadramento em zonas de maior proteção, como dispõe a legislação.

\subsection{Cobertura do solo do Parque Estadual Mata do Pau Ferro}

Foram registradas quatro classes de cobertura do solo na Unidade de Conservação: Floresta Estacional Semidecidual Montana; Áreas degradadas/regeneração; Solo exposto; e corpo d'água representado pela barragem Vaca Brava. Conforme mostra a Figura 7, existe a predominância da cobertura pela Floresta Estacional Semidecidual Montana, que de acordo com o IBGE (2012), constitui uma das formações do bioma Mata Atlântica, que ocorre em altitudes superiores a 500m. E de acordo com Tabarelli e Santos (2004) é a formação predominante nos Brejos de Altitude do Nordeste.

A vegetação apresenta menor densidade da cobertura nas bordas do Parque, sendo estas mais vulneráveis à ação humana, e apresenta maior densidade da cobertura vegetal no interior do Parque, quase sempre associada às áreas com maior declividade. A densidade visual apresentada pela vegetação foi um dos critérios utilizados para o estabelecimento de áreas de maior proteção, como a zona primitiva. O percentual de cobertura do solo para as quatro classes é apresentado na Tabela 2.

A classe de Áreas degradadas/regeneração constitui áreas em que a vegetação se encontra em diversos estágios de regeneração, predominando uma vegetação arbustiva e herbácea. Antes da implantação da Unidade de Conservação, o atual território que constitui o Parque estava ocupado por atividades como a pecuária e agricultura. Após a intervenção do poder público para implantação da Unidade de Conservação, as áreas degradadas entraram em processo de regeneração natural. 


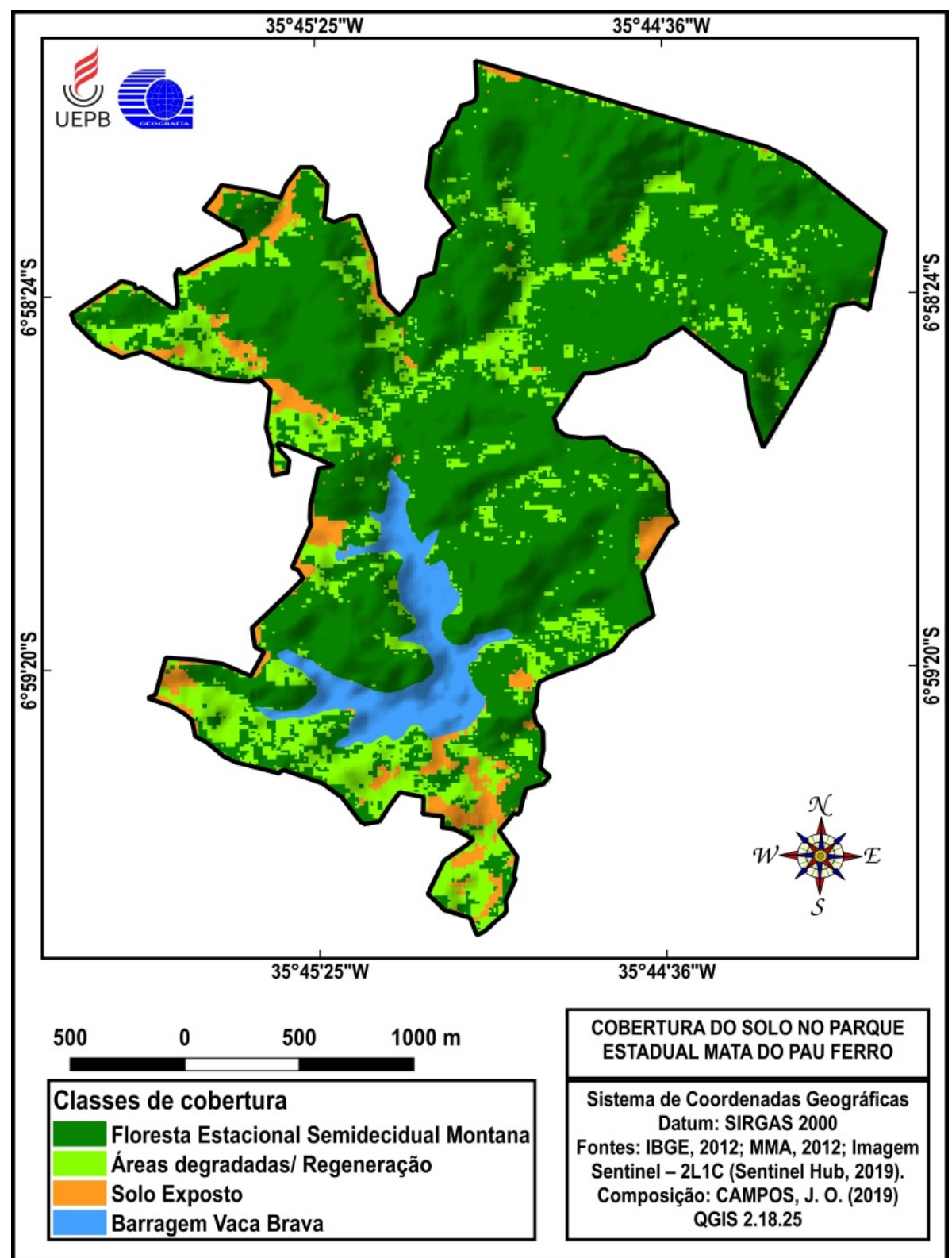

Figura 7: Cobertura do solo do Parque Estadual Mata do Pau Ferro

Entretanto, os usos conflituosos das terras do Parque, mesmo depois da implantação da Unidade de Conservação, podem estar impedindo o desenvolvimento de estágios mais avançados de regeneração, principalmente nas áreas que marginam a barragem Vaca Brava, e ao longo do curso dos rios nas porções centrais e interioranas. Tais áreas foram priorizadas para zonas de recuperação.

Tabela 2: Classes de cobertura do solo e percentual de área

\begin{tabular}{c|c|c|c}
\hline \multicolumn{2}{c|}{ Classes } & Área (ha) & Percentual (\%) \\
\hline Floresta Estacional Semidecidual Montana & & 440,43 & 72,44 \\
\hline Áreas degradadas/ regeneração & & 99,01 & 16,29 \\
\hline Solo Exposto & & 33,22 & 5,46 \\
\hline Barragem Vaca Brava & 35,30 & 5,81 \\
\hline Total & $\mathbf{6 0 7 , 9 6}$ & $\mathbf{1 0 0}$ \\
\hline
\end{tabular}


As áreas de solo exposto correspondem às áreas em que o processo de regeneração da vegetação ainda não avançou o suficiente para permitir a cobertura do solo, havendo também áreas em que, devido à manutenção de pastagens e atividades agrícolas, se encontram em processo de degradação.

A barragem Vaca Brava cobre um percentual de 5,81\% do Parque e, devido ao fluxo regular de pessoas em suas imediações, alguns pontos apresentam solo exposto. $O$ reservatório e as estradas circundantes foram inseridos em zona de uso conflitante, em vista que já estavam em funcionamento antes da implantação da Unidade de Conservação. Os usos conflitantes do Parque serão abordados em um tópico adiante, junto com o mapeamento dos conflitos.

\subsection{Mapeamento das trilhas do Parque Estadual Mata do Pau Ferro}

No mapeamento das trilhas foram consideradas apenas as trilhas que são mantidas pelos guias, pelo que trilhas aleatórias abertas por usuários ou moradores das áreas adjacentes não foram consideradas. Todas as trilhas têm como ponto inicial o Centro de Turismo Jonas Camelo de Souza, que está localizado na entrada do Parque. As trilhas utilizadas pelos guias são as seguintes: Trilha do Cumbe; Trilha dos Miguéis; Trilha das Flores; e Trilha da Barragem. A Figura 8 apresenta o mapeamento das trilhas.

A atividade turística no Parque ocorre de maneira informal, isto é, não há um controle sobre o número de usuários, e a circulação de pessoas é livre. Existem três guias que residem nas proximidades do Parque, que realizam o trabalho de condução nas trilhas. Os mesmos já realizaram cursos de capacitação na área ambiental para melhor desenvolver a atividade na Unidade de Conservação. Os guias locais ao realizarem o trabalho cobram uma taxa em dinheiro por pessoa, tendo como referência a quilometragem percorrida nas trilhas. Muitas vezes ocorre a integração de duas ou mais trilhas, para que seja alcançada a quimoletragem desejada pelos visitantes. Turistas e grupos de visitantes experientes costumam percorrer as trilhas sem auxílio dos guias, realizando o percurso por conta própria.

A maior parte dos usuários do Parque enquadram-se nos seguintes grupos: moradores locais, guias, estudantes da educação básica e superior, pesquisadores, turistas experientes e grupos da terceia idade. A maior parte dos usuários vem em buscar de lazer, recreação e realização de pesquisas. Não há sinalização nas trilhas, existindo apenas alguns retalhos de tecidos coloridos nas árvores deixados pelos guias para servir de orientação em relação ao percurso da trilha percorrida. Regularmente são encontradas nas trilhas embalagens de comida e bebidas, consequência da atenuada fiscalização. Na entrada do Parque existem apenas placas com orientações aos visitantes para a conduta nas trilhas, representam a única sinalização oficial do local no tocante à atividade turística. $O$ mapa também mostra os percursos de integração (Figura 8), que são utlizados como conexão entre as trilhas, e também como forma de estender trajeto visando mais tempo de caminhada. 


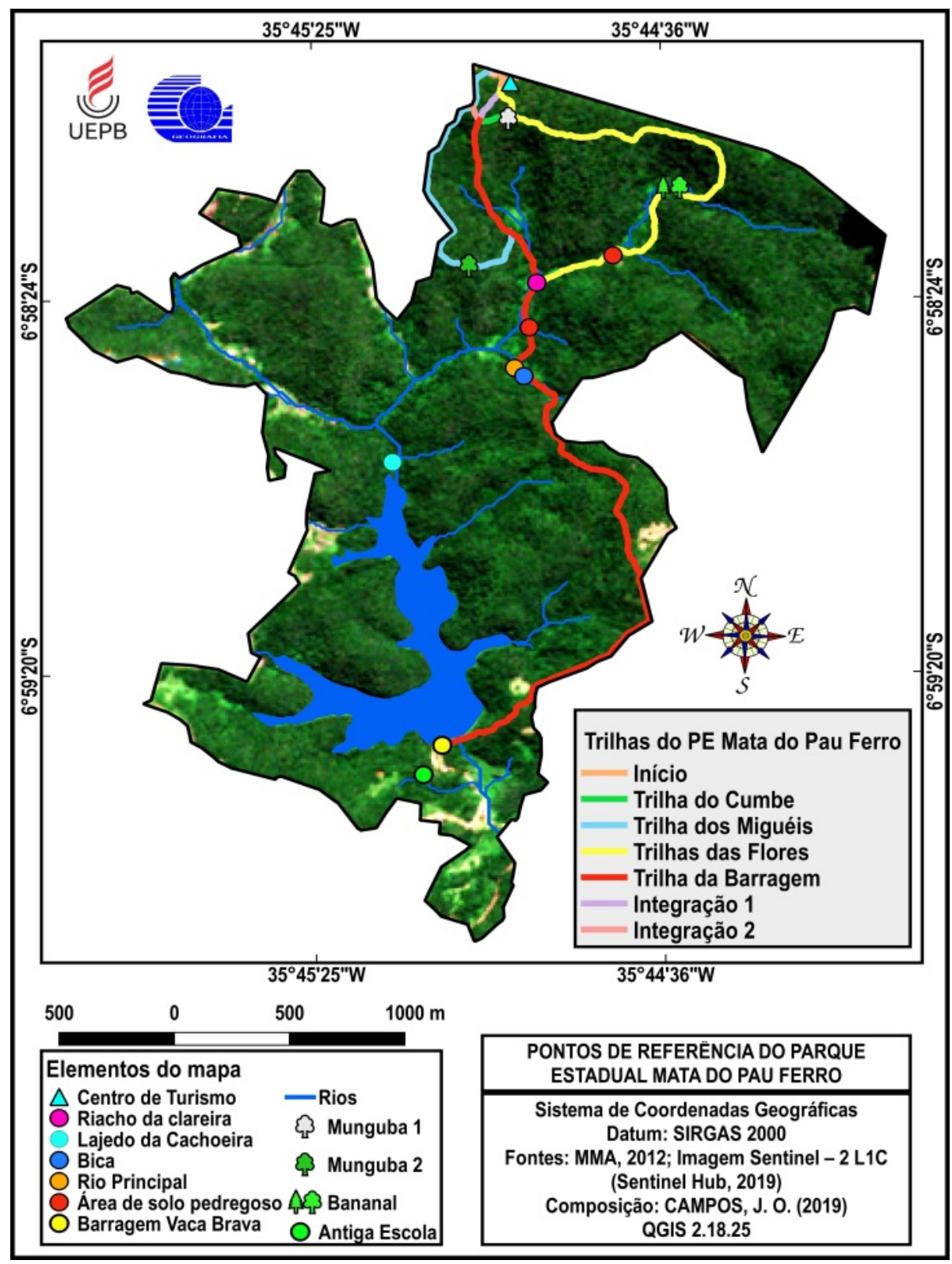

Figura 8: Mapeamento das trilhas do Parque Estadual Mata do Pau Ferro

A Trilha do Cumbe é a mais curta de todas e também uma das mais utilizadas, principalmente por insituições de ensino para realização de trilha interpretativa. A Trilha da Barragem apresenta a maior extensão e está entre as mais utlizadas, em parte devido à barragem Vaca Brava que funciona como atrativo. A porção noroeste do Parque, área compreendia pela Trilha do Cumbe, Trilha dos Miguéis, Trilha das Flores e em parte pela Trilha da Barragem, corresponde ao perímetro mais utilizado e frequentado. Nesse sentido, a área foi enquadrada em uma zona de transição entre maior e menor proteção.

Os usos conflitantes no Parque foram classificados em: uso agrícola, compreendo áreas de lavouras e cultivos diversificados; uso pecuário, compreendendo as áreas utlizadas como pastagens; e habitações e atividades antrópicas, abrangendo áreas com casas abandonadas e habitadas, criação de animais e outras atividades de 
subsistência (Figura 9). Tal conjuntura conflita com a política de Proteção Integral das Unidades de Conservação, pois inviabiliza os fins de preservação, na medida em que ocorre o uso direto dos recursos naturais, afetando assim os processos ecológicos e induzindo perturbações aos ecossistemas.

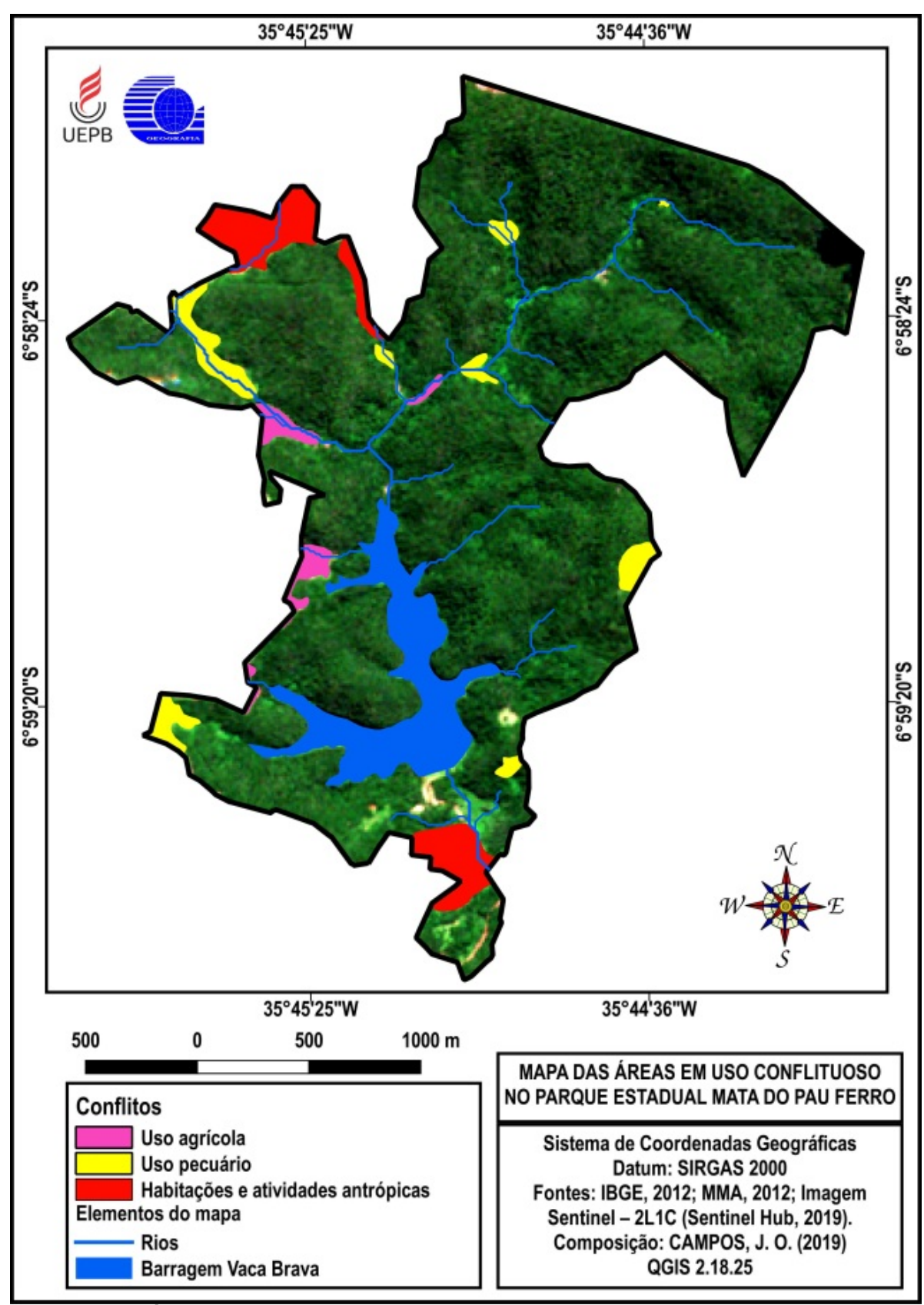

Figura 9: Áreas de uso conflituoso no Parque Estadual Mata do Pau Ferro

Os conflitos materializados atualmente como uso agrícola, pecuário, habitações e atividades antrópicas enquadram-se nas áreas anteriormente identificados por Silva (2007), em 2001 e 2003, como sendo de culturas permanentes e temporárias, realidade na qual o autor evidenciou o quadro de degradação ambiental sofrido pela Reserva. Atualmente, dezoito anos depois, parte das áreas cultivadas ainda se 
mantém, outras foram suprimidas, encontrando-se hoje em processo de regeneração natural.

Para Cavalcante (2008) a ausência de investimentos nestas áreas e a falta de conscientização das populações locais acabam por agravar os quadros de degradação. Até o momento de finalização deste trabalho, de acordo com a SUDEMA, o Plano ainda não havia sido implementado, embora estivesse construído. Diante dessa realidade, depreende-se que a SUDEMA tem conhecimento das condições ambientais em que se encontram o Parque, e em virtude da falta de recursos, não pode garantir uma fiscalização efetiva da área protegida.

\subsection{Proposta de Zoneamento Ambiental para o Parque Estadual Mata do Pau Ferro}

O zoneamento de Unidades de Conservação - UC corresponde a uma ferramenta de gestão que possibilita o ordenamento territorial para melhores resultados no quadro de manejo, favorecendo, assim, o alcance dos objetivos estabelecidos para a Unidade Conservação. Para a elaboração da proposta de Zoneamento Ambiental do Parque Estadual Mata do Pau Ferro, foram utilizados os critérios do IBAMA (2002) para o estabelecimento das zonas: grau de intervenção da vegetação; variabilidade ambiental; representatividade das zonas; áreas de transição; suscetibilidade ambiental; potencial de visitação; potencial para Conscientização Ambiental; presença de infraestrutura; uso conflitante; e presença de população. Além destes, foram considerados os seguintes pontos: condições ambientais apresentadas através dos mapas, os usos, a necessidade de proteção das áreas e o quadro de manejo presente na Unidade de Conservação.

Para ajuste de localização e limites das zonas foram considerados os seguintes critérios: nível de pressão antrópica; acessibilidade; gradação de uso; percentual de proteção; e limites identificáveis na paisagem. Os critérios foram tomados como norte para elaboração de mapas e realização da pesquisa de campo. A Figura 10 apresenta a proposta de Zoneamento Ambiental elaborada.

A Zona Primitiva mostrou-se a mais representativa (Tabela 3), e junto com a Zona Intangível constituem as áreas de maior proteção do Parque, cobrindo um percentual de 57,54\%. A Zona de Recuperação evidenciou menor percentual de cobertura, e em vista do caráter temporário, no futuro a zona poderá ser dissolvida e incorporada em zonas permanentes de maior proteção. 


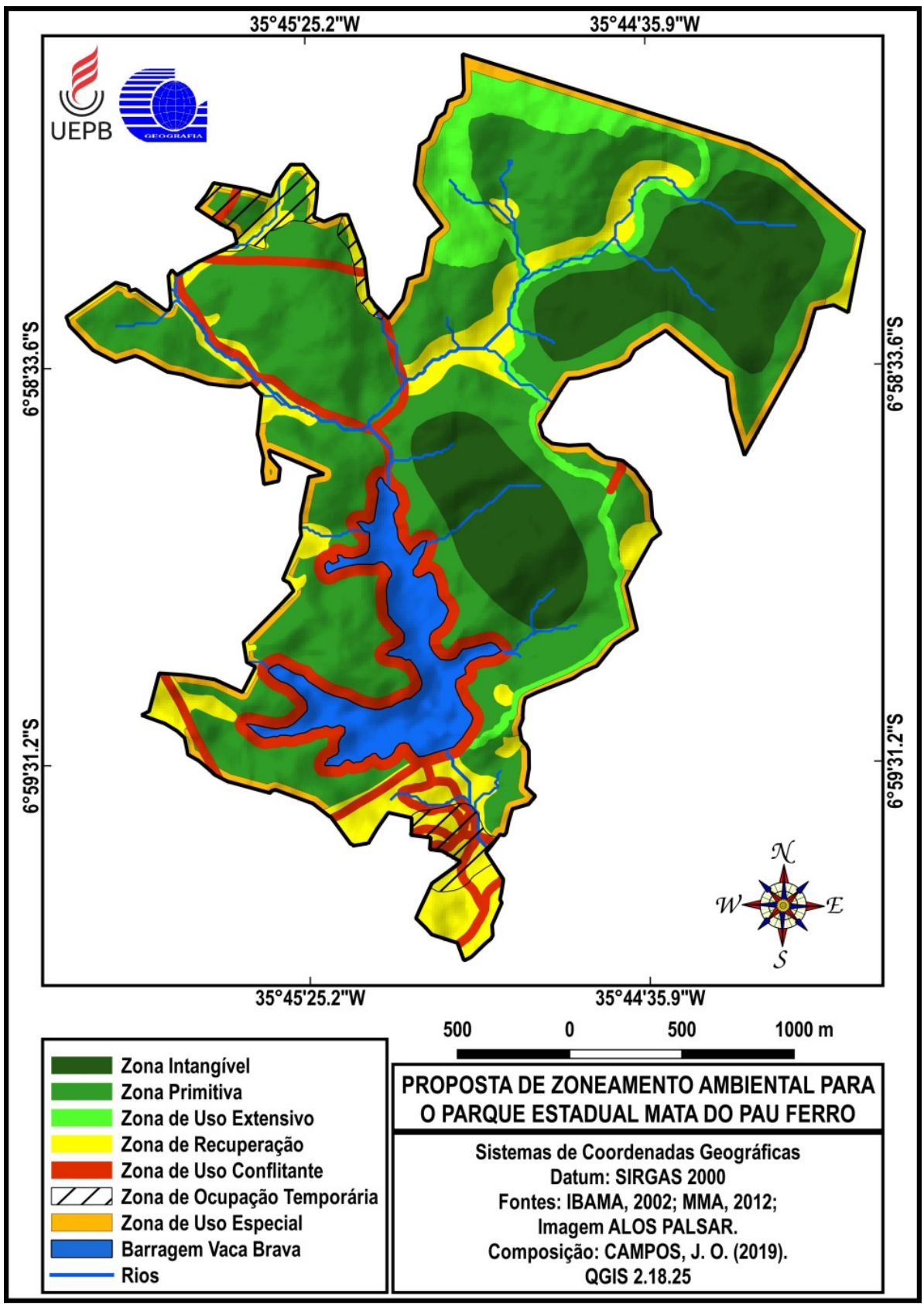

Figura 10: Proposta de Zoneamento Ambiental para o Parque Estadual Mata do Pau Ferro

Tabela 3: Área e percentual de cobertura das zonas

\begin{tabular}{|c|c|c|}
\hline Zonas & Área (ha) & Percentual (\%) \\
\hline Zona Intangível & 93,59 & 15,39 \\
\hline Zona Primitiva & 256,23 & 42,15 \\
\hline Zona de Uso Extensivo & 106,27 & 17,48 \\
\hline Zona de Recuperação & 40,42 & 6,65 \\
\hline Zona de Uso Conflitante & 68,71 & 11,30 \\
\hline Zona de Uso Especial & 42,74 & 7,03 \\
\hline Total & 607,96 & 100 \\
\hline
\end{tabular}


As características gerais de cada zona e seus pontos referência para identificação dos limites são apresentadas a seguir:

Zona Intangível: Abrange áreas de maior primitividade e densidade da vegetação. Localizam-se nas porções mais interioranas do Parque, associadas a altitudes mais elevadas. Seus limites têm como referência a Área de Solo Pedregoso, o Bananal, a localização das trilhas, nascentes e rios.

Zona Primitiva: Abrange áreas de vegetação primitiva, com baixa intervenção humana, apresentando características de transição entre as zonas de Uso Extensivo e Intangível. Contém áreas em estágios avançados de regeneração da vegetação e compreende a maior área do Parque. Seus limites têm como referência as Mungubas 1 e 2 (Eriotheca crenulaticalyx A. Robyns.) e a localização das demais zonas, uma vez que faz contato com todas as demais em diversos pontos do Parque.

Zona de Uso Extensivo: Abrange áreas cobertas por vegetação, apresentando pontos com baixo grau de intervenção humana. Contém as trilhas e os pontos mais visitados do Parque. Estende-se para o interior do Parque em virtude da Trilha da Barragem. Seus limites têm como referência o Centro de Visitantes, o limite das trilhas, as Mungubas 1 e 2, os rios e as áreas em regeneração.

Zona de Recuperação: Abrange áreas em regeneração e também com alto grau de intervenção humana. Compreende também áreas de uso conflituoso. Seus limites têm como referência os limites do Parque, uma vez que a maior parte dos pontos de recuperação ocorre nas bordas. Na parte central do Parque o limite é a zona de Uso Extensivo e a localização do rio principal.

Zona de Uso Conflitante: Abrange as áreas ocupadas pela barragem Vaca Brava e sua APP, as estradas de acesso à barragem, as trilhas e as estradas que cruzam o Parque instaladas antes da implantação da Unidade de Conservação. Seus limites detêm-se à própria localização destes elementos na paisagem. Com exceção da zona Intangível, esta zona limita-se com todas as demais.

Zona de Ocupação Temporária: Abrange três pontos localizados na porção sul e noroeste do Parque, onde se encontram habitações abandonas e habitadas, além da manutenção de atividades diversificadas. É uma zona de caráter provisório, uma vez que, realocada a população, esta será adicionada em zonas permanentes. Seus limites têm referência nas zonas de Recuperação e Uso Conflitante na porção sul do Parque e a noroeste, do mesmo modo, os limites do Parque e a zona de Recuperação funcionam como os limites desta.

Zona de Uso Especial: Abrange uma faixa localizada na periferia do Parque, apresentando uma vegetação com considerável manejo, em vista de estar vulnerável aos agentes externos e à ameaça da extração de madeira. Encontra-se fragmentada ao longo do Parque, em virtude de ser cortada pelas zonas de Recuperação e de Uso Conflitante. Na periferia do Parque compreende uma faixa de $35 \mathrm{~m}$ a partir do limite da Unidade de Conservação e no centro de turismo projeta-se $50 \mathrm{~m}$ para interior, em 
virtude das instalações e habitações ali presentes. Seus limites são as zonas próximas. Com exceção da zona Intangível, limita-se com todas as demais.

Com o zoneamento, cada zona passa a necessitar de usos diferenciados, por forma a cumprir os seus objetivos e funções para as quais foi estabelecida, proporcionando, assim, melhorias no quadro do seu manejo e maior proteção, uma vez que serão manejadas segundo as normas estabelecidas após a delimitação. O Quadro 3, elaborado a partir das indicações do IBAMA (2002), aponta os graus de intervenção e as atividades admitidas para cada zona.

Quadro 3: Usos admitidos para as zonas do Parque Estadual Mata do Pau Ferro

\begin{tabular}{|c|c|c|}
\hline ZONEAMENTO & $\begin{array}{c}\text { GRAU DE } \\
\text { INTERVENÇÃo }\end{array}$ & USOS ADMITIDOS \\
\hline Zona Intangível & $\begin{array}{c}\text { Nenhuma } \\
\text { ou baixa }\end{array}$ & $\begin{array}{c}\text { Pesquisa restritiva, quando não possível de ser realizada } \\
\text { em outras zonas; monitoramento; proteção, em casos de } \\
\text { evidência de caça ou fogo. }\end{array}$ \\
\hline Zona Primitiva & $\begin{array}{c}\text { Nenhuma } \\
\text { ou baixa }\end{array}$ & $\begin{array}{c}\text { Monitoramento, proteção, educação ambiental, visitação } \\
\text { restritiva e de baixo impacto, não sendo admitida a } \\
\text { implantação de qualquer infraestrutura. }\end{array}$ \\
\hline $\begin{array}{c}\text { Zona de Uso } \\
\text { Extensivo }\end{array}$ & Média & $\begin{array}{c}\text { Pesquisa, monitoramento, proteção, visitação menos } \\
\text { restritiva, trilhas, sinalização e pontos de descanso. }\end{array}$ \\
\hline $\begin{array}{c}\text { Zona de Uso } \\
\text { Especial }\end{array}$ & Alta & $\begin{array}{c}\text { Estrutura necessária à administração, pesquisa e } \\
\text { proteção. }\end{array}$ \\
\hline $\begin{array}{c}\text { Zona de } \\
\text { Recuperação }\end{array}$ & Alta & $\begin{array}{c}\text { Pesquisa, proteção e educação ambiental. O acesso a } \\
\text { esta zona será restrito aos pesquisadores e pessoal } \\
\text { técnico. }\end{array}$ \\
\hline $\begin{array}{c}\text { Zona de Uso } \\
\text { Conflitante }\end{array}$ & Alta & $\begin{array}{c}\text { Fiscalização, proteção, manutenção de infraestrutura } \\
\text { específica e serviços inerentes aos empreendimentos de } \\
\text { utilidade pública. }\end{array}$ \\
\hline $\begin{array}{c}\text { Zona de } \\
\text { Ocupação } \\
\text { Temporária }\end{array}$ & Alta & $\begin{array}{c}\text { Fiscalização, proteção, educação ambiental e atividades } \\
\text { previstas em termo de compromisso. }\end{array}$ \\
\hline
\end{tabular}

Fonte: IBAMA (2002)

Diante disto, verifica-se que o zoneamento se evidenciou como uma ferramenta de ordenamento do território da UC, condicionando um cenário para alcance dos objetivos propostos para uma Unidade de Conservação representante do grupo de Proteção Integral. Faz-se necessário ressaltar que os limites das zonas podem ser remanejados, buscando atingir melhores resultados no manejo do Parque. Do mesmo modo, as zonas podem ser expandidas ou retraídas, para uma melhor delimitação, ou mesmo em conformidade com as necessidades de manejo.

A Zona Intangível e a Zona Primitiva juntas somam 57,54\% das áreas que apresentam maior primitividade no Parque, necessitando, assim, de medidas para garantir a sua manutenção e preservação. Pois, encontrando-se aí condições naturais mais preservadas, tais áreas funcionam como núcleos de recomposição da fauna e flora no Parque em casos de perturbações ambientais de origem antrópica, principalmente nas zonas marginais que se encontram nas bordas, estando assim, mais susceptíveis às ameaças externas. 
De forma geral, com o zoneamento foram estabelecidas sete zonas distribuídas em três graus de intervenção (baixo, médio e alto), havendo predominância do primeiro, o que demonstra que o Parque comporta áreas bem preservadas. Das zonas cridas, duas são de caráter temporário: Zona de Recuperação e Zona de Ocupação Temporária. A primeira poderá ser dissolvida quando apresentar estágios avançados de regeneração, sendo assim incorporada a zonas permanentes. Do mesmo, quando resolvidos os conflitos que caracterizam a segunda zona, esta será dissolvida.

Os resultados aqui apresentados fornecem uma base de dados que permite o alcance de novas percepções sobre a gestão da biodiversidade e a estratégias de manejo dos recursos naturais contidos no território protegido. Apontam também para a necessidade de implantação de atividades que potencializem a preservação e as práticas de educação ambiental no Parque, abrangendo também as comunidades do entorno, com o intuito de uma maior participação destas na gestão e proteção do Parque, pois estas são fundamentais para que sejam alcançados os objetivos traçados para a Unidade de Conservação.

\section{Conclusões}

O Parque Estadual Mata do Pau Ferro, apesar das ameaças e degradação ambiental, possui áreas bem preservadas, localizadas principalmente nas cotas de maior altitude. Existem também pontos que estão sofrendo significativa pressão antrópica, em virtude do uso de áreas do Parque para fins agrícolas e pecuários, principalmente nas várzeas, onde ocorrem condições favoráveis para a manutenção destas. Os usos conflituosos têm impedido os processos de regeneração natural de atingirem estágios mais avançados, resultando na continuidade de áreas abertas e clareiras no interior do Parque.

A Zona de Uso Extensivo do Parque, por comportar amostras dos principais recursos naturais, configurar-se como uma área de média intervenção humana e comportar vegetação primitiva, apresenta potencial para Educação Ambiental, realização de pesquisas científicas, trilhas e visitação.

As cotas mais elevadas do Parque ocorrem na porção norte, onde também se encontram as vertentes de maior declividade e maior vulnerabilidade à degradação ambiental. As áreas de maior altitude apresentam maior primitividade da vegetação, provavelmente em função das condições de acesso não favoráveis.

O Parque tem significativa contribuição para a manutenção dos recursos hídricos na microbacia da barragem Vaca Brava, uma vez que cobre parcialmente a sua área de captação e comporta o reservatório no seu interior. A drenagem do Parque recebe maior importância em virtude da maior parte da área de captação da bacia se encontrar coberta por pastagens.

O zoneamento aqui apresentado, se aplicado ao Parque, é um instrumento que pode desencadear mais indicações de locais com usos conflitantes. Sua implementação implicará na mudança de usos atuais que são realizados em algumas áreas do Parque. 
No entanto, identificar os conflitos de uso, áreas prioritárias e proposição de uma nova conjuntura de manejo, contribuiu para a apresentação e visualização de uma realidade mais adequada aos fins da Unidade de Conservação. Ao mesmo tempo, também aponta para necessidade de maior fiscalização dos órgãos gestores sobre o território do Parque, tendo em vista que os conflitos nele instalados remontam ao período de instalação da Unidade de Conservação.

\section{Bibliografia}

Ab'Sáber, A. N. (1992). A serra do japi, sua origem geomorfológica e a teoria dos refúgios. In Morellato, L. P. C. (Org). História Natural da Serra do Japi, (pp. 12-23). Campinas: Ed. UNICAMP.

Brasil (2000). Lei Federal no 9.985, de 18 de julho de 2000. Regulamenta o art. 225, § 10, incisos I, II, III e VII da Constituição Federal, institui o Sistema Nacional de Unidades de Conservação da Natureza e dá outras providências. Brasília - DF: Presidência da República. Disponível em: http://www.planalto.gov.br/ccivil 03/leis/19985.htm.

Brasil (2010). Conselho Nacional do Meio Ambiente (CONAMA). Resolução $n^{\circ}$ 428, de 17 de dezembro de 2010. Dispõe, no âmbito do licenciamento ambiental sobre a autorização do órgão responsável pela administração da Unidade de Conservação (UC), de que trata o $\S$ $3^{\circ}$ do artigo 36 da Lei $n^{\circ} 9.985$ de 18 de julho de 2000 , bem como sobre a ciência do órgão responsável pela administração da UC no caso de licenciamento ambiental de empreendimentos não sujeitos a EIA-RIMA e dá outras providências. Brasília, DF: Presidência da República. Disponível em: http://www2.mma.gov.br/port/conama/legiabre.cfm?codlegi=641.

Brasil (2012). Lei $n^{\circ} 12.651$, de 25 de maio 2012. Dispõe sobre a proteção da vegetação nativa; altera as Leis $n^{\circ}$ s 6.938, de 31 de agosto de 1981, 9.393, de 19 de dezembro de 1996, e 11.428, de 22 de dezembro de 2006; revoga as Lei $n^{\circ}$ s 4.771, de 15 de setembro de 1965, e 7.754, de 14 de abril de 1989, e a Medida Provisória n².166- 67, de 24 de agosto de 2001; e dá outras providências. Brasília, DF: Presidência da República. Disponível em: https://www2.camara.leg.br/legin/fed/lei/2012/lei-12651-25-maio-2012613076-publicacaooriginal-136199-pl.html.

Brasil (2019). Ministério do Meio Ambiente. Cadastro Nacional de Unidades de Conservação. Tabela consolidada das Unidades de Conservação. Brasília: MMA.

Castro Júnior, E., Coutinho, B. H., Freitas, L. E. (2009). Gestão da biodiversidade e áreas protegidas. In Guerra, A. J. T., Coelho, M. C. N. (Orgs). Unidades de Conservação: abordagens e características geográficas, (pp. 25-65). Rio de Janeiro: Bertrand Brasil.

Cavalcante, M. B. (2008). Parque Estadual da Pedra da Boca/PB: Um olhar sobre o planejamento do ecoturismo em Unidades de Conservação na Paraíba. Caderno Virtual de Turismo, 8(2), 69-80. Disponível em: http://www.ivt.coppe.ufrj.br/caderno/index.php/caderno/article/viewFile/243/180.

Dorst, J. (1973). Antes que a natureza morra: por uma ecologia política. Tradução: Rita Buongermino. São Paulo: Edgard Blucher.

Françoso, R. D., Brandão, R. A., Batista, V. B. G. V. (2011). Identificação de áreas relevantes para conservação com base em indicadores biológicos: subsídio ao zoneamento de dois parques nacionais no cerrado brasileiro. Caminhos de Geografia, 40, 106-118. 
Guerra, A. J. T., Lopes, P. B. M. (2015). APA de Petrópolis: Um estudo das características geográficas. In Guerra, A. J. T., Coelho, M. C. N. (Orgs). Unidades de Conservação: abordagens e características geográficas, (pp. 113-142). Rio de Janeiro: Bertrand Brasil.

IBAMA, Instituto Brasileiro do Meio Ambiente e dos Recursos Naturais Renováveis (2002). Roteiro metodológico de planejamento: Parque Nacional, Reserva Biológica, Estação Ecológica. Brasília - DF: IBAMA.

IBGE, Instituto Brasileiro de Geografia e Estatística (2008). Produção Agrícola Municipal 2007. Rio de Janeiro: IBGE.

IBGE, Instituto Brasileiro de Geografia e Estatística (2012). Manual Técnico da Vegetação Brasileira. Rio de Janeiro: IBGE. Disponível em: https://biblioteca.ibge.gov.br/visualizacao/livros/liv63011.pdf.

IBGE, Instituto Brasileiro de Geografia e Estatística (2019). Estimativas da população residente para os municípios e para as unidades da federação com data de referência em $1^{\circ}$ de julho de 2019: notas metodológicas. Rio de Janeiro: IBGE. Disponível em: https://biblioteca.ibge.gov.br/visualizacao/livros/liv101662.pdf.

MEDEIROS, R. (2006). Evolução das tipologias e categorias de áreas protegidas no brasil. Ambiente \& Sociedade, 1, 41-64. http://www.scielo.br/pdf/asoc/v9n1/a03v9n1.pdf.

PARAÍBA (1985). Governo do Estado da Paraíba. Secretaria de Educação. Universidade Federal da Paraíba. Atlas geográfico do Estado da Paraíba. João Pessoa: Grafset.

PARAÍBA (1992). Decreto no 14.832, de 19 de outubro de 1992. Cria a Reserva Ecológica da "MATA DO PAU FERRO" e dá outras providências. Diário Oficial [do] Estado da Paraíba: Poder Executivo, João Pessoa. Disponível em: https://acervo.socioambiental.org/sites/default/files/documents/J0D00002 0.pdf.

PARAÍBA (2005). Decreto $n^{\circ} 26.098$, de 04 de agosto de 2005. Cria o Parque Estadual MATA DO PAU FERRO, no Estado da Paraíba, e dá outras providências. Diário Oficial [do] Estado da Paraíba: Poder Executivo, João Pessoa. Disponível em: http://www.pbprev.pb.gov.br/pbprev/a-previdencia/legislacao/36A5Cd01.pdf.

Pfaltzgraff, P. A. S., Torres, F. S. M., Silva, E. P., Alcantara, V. C. (2016). Geodiversidade: adequabilidades/potencialidades e limitações frente ao uso e à ocupação. In Torres, F. S., Silva, E.P. (Orgs).Geodiversidade do estado da Paraíba, (pp. 51-84). Recife: CPRM.

Santos, H. G., Jacomine, P. K. T., Anjos, L. H. C., Oliveira, V. A., Lumbreras, J. F., Coelho, M. R., Almeida, J. A., Araújo Filho, J. C., Oliveira, J. B., Cunha, T. J. F. (2018). Sistema Brasileiro de Classificação de Solos SiBCS. Brasília: Embrapa.

Silva, M. C. (2007). Degradação ambiental na Reserva Ecológica Estadual da Mata do Pau Ferro - Areia/PB. Dissertação de Mestrado em Geografia, Universidade Federal da Paraíba, João Pessoa, Brasil.

SUDEMA, Superintendência de Administração do Meio Ambiente (2018). Unidades de Conservação da Paraíba são destaque na Semana do Meio Ambiente. João Pessoa: Governo da Paraíba. Disponível em: https://der.pb.gov.br/sudema/noticias/unidades-deconservacao-da-paraiba-sao-destaque-na-semana-do-meio-ambiente.

Tabarelli, M., Santos, A. M. M. (2004). Uma breve descrição sobre a história natural dos Brejos Nordestinos. In Porto, K. C., Cabral, J. J. P., Tabarelli, M. (Orgs). Brejos de altitude em 
Pernambuco e Paraíba: história natural, ecologia e conservação (pp. 17-24). Brasília: Ministério do Meio Ambiente.

Artigo recebido em/ Received on: 22/12/2019

Artigo aceite para publicação em/ Accepted for publication on: 22/05/2020 